\title{
Analisis Distribusi Pemasaran Udang Windu (Penaeus monodon) di Kelurahan Margomulyo, Kecamatan Balikpapan Barat Kota Balikpapan
}

\section{(The Marketing Distribution Analysis of Tiger Shrimp (Penaeus monodon) in Kelurahan Margomulyo, Balikpapan Barat District Balikpapan City)}

\author{
Abdul Hadi Bone \\ Manajemen Agribisnis STIPER Muhammadiyah Tanah Grogot, Paser \\ hadibone199@yahoo.co.id
}

\begin{abstract}
ABSTRAK
Kawasan Margomulyo adalah kawasan perlindungan yang memberikan berbagai manfaat untuk menunjang kehidupan bagi masyarakat. Penelitian ini bertujuan mengetahui: (i) jumlah lembaga pemasaran pada distribusi pemasaran udang windu, (ii) jalur pemasaran yang ada pada pemasaran udang windu oleh petani kolam di Kelurahan Margomulyo Kecamatan Balikpapan Barat Kota Balikpapan, (iii) marjin pemasaran pada distribusi pemasaran udang windu. Penelitian ini dilaksanakan di Kawasan Margomulyo pada bulan September-Desember 2016. Metode penelitian menggunakan metode survei lapangan dengan mewancarai masyarakat nelayan serta penelusuran pustaka. Untuk menganalisis fungsifungsi pemasaran, dianalisis berdasarkan fungsi-fungsi ditiap lembaga pemasaran, sedangkan analisis distribusi margin dilakukan dengan menghitung biaya-biaya pemasaran baik ditingkat konsumen maupun produsen. Hasil penelitian pola pemasaran udang bintik di Kawasan Margomulyo menunjukkan ada empat pola saluran distribusi pemasaran yaitu : I (produsen-konsumen), II ( produsen-pengecer-konsumen), III (produsen-pengumpul-pengecer-konsumen) dan IV (produsen-pengumpul-pengecer-pedagang kelilingkonsumen).Tingkat distribusi pemasaran udang windu pada saluran pola II (Produsen-PengecerKonsumen) lebih dominan digunakan karena alur distribusi pemasaran tersebut relatif lebih pendek sehingga memotong alur distribusi pemasaran sampai pada tingkat konsumen akhir, sehingga dapat menekan biaya tambahan lainya. Hal ini dapat dilihat berdasarkan nila share yang diperoleh sebesar 75,05\%, harga jual udang windu pada konsumen akhir sebesar 37.000, sedangkan rata-rata harga jual sebesar Rp. 27.767,-, Margin pemasaran sebesar Rp. 9.233,- dengan keuntungan sebesar 5.881. Nilai tersebut menunjukkan keuntungan bagi petani tambak udang windu (produsen) yang menjanjikan sebagai pelaku usaha utama budidaya udang windu.
\end{abstract}

Kata Kunci: Pemasaran, udang windu, produsen, konsumen, pengecer.

\section{ABSTRACT}

Margomulyo area is a protected area that provides various benefits to support life for the community. This study aims to determine: (i) the number of marketing institutions in the distribution of marketing of tiger shrimp, (ii) the marketing channels available in the marketing of tiger shrimp by pond farmers in Margomulyo Village, Balikpapan Barat District, Balikpapan City, (iii) marketing margins in the distribution of black shrimp marketing. This research was carried out in Margomulyo area in SeptemberDecember 2016. The research method used a field survey method by interviewing fishing communities and literature. To marketing functions analyze, it is analyzed based on the functions of each marketing agency, while the analysis of margin distribution is done by calculating marketing costs both at the consumer and producer level. The results of the study of marketing patterns of freckle shrimp in the Margomulyo Region indicate that there are four patterns of marketing distribution channels, namely: I (producer-consumer), II (consumer-retailer), III (producer-retailer-consumer) and IV (producer-gatherer) -customer-sellersretailers). The marketing distribution of tiger shrimp on pattern channel II (Producers-RetailersConsumers) is more dominantly used because the marketing distribution channel is relatively shorter so it cuts the marketing distribution flow to the final consumer level, so it can suppress other additional costs. This can be seen based on the value of the share obtained at $75.05 \%$, the selling price of tiger shrimp in the final consumer is 37,000, while the average selling price is Rp. 27,767,-. Marketing margin of Rp. 9,233,- with a profit of 5,881. This value shows the advantages for the promising shrimp producer (producer) farmers as the main business actors of tiger shrimp cultivation.

Keywords: Marketing, tiger shrimp, producers, consumers, retailers. 


\section{PENDAHULUAN}

Indonesia merupakan salah satu negara penghasil udang terbesar didunia. Diketahui berdasarkan Depdag (2009) bahwa realisasi ekspor / devisa yang dihasilkan udang Indonesia pada tahun 2006 sebesar US\$ 943.998.000, pada tahun 2007 sebesar US\$ 791.854.000 dan meningkat menjadi 1.055.805.000 sampai akhir bulan Agustus 2008. Nilai ekspor turun dari US\$ 1 miliar pada Januari-Agustus 2008 menjadi hanya US\$ 314 juta di 2009. "Harga merosot karena permintaannya juga melorot akibat AS mengurangi konsumsi udang. Pada tahun 2011 ekspor udang mencapai 152,053 ton atau mengalami kenaikan dibanding 2010 yang hanya mencapai 145,092 ton. Namun, jumlah itu turun drastis jika dibandingkan dengan tahun 2007 yang mencapai 169,329 ton (Murtidjo, 2003). Udang adalah salah satu sumberdaya perikanan yang mengandung zat-zat gizi yang tinggi bagi tubuh, juga merupakan salah satu komoditi yang memiliki nilai jual yang tinggi baik di pasar domestik maupun mancanegara (BPS RI, 2016).

Secara konseptual sistem agribisnis dapat diartikan sebagai semua aktivitas atau kegiatan mulai dari pengadaan, penyaluran sarana produksi sampai dengan pemasaran produk yang dihasilkan oleh usaha tersebut dan agroindustri yang terkait. Salah satu bidang agribisnis yang telah dikembangkan adalah disektor perikanan (Widya, 2014). Semakin banyak permintaan konsumsi terhadap udang windu di pasar, mengakibatkaan adanya persaingan yang ketat antara petambak dalam berproduksi. Dalam menghadapi hal ini diperlukan setrategi pemasaran yang tepat agar dapat bersaing dengan petambak lainnya dan dapat memperluas pasar. Salah satu cara untuk dapat memperluas pasar yaitu dengan mengefektifkan pemasaran yang efesiensi dan memperlancar arus barang dari produsen ke konsumen, melalui efesiensi pemasaran ini, harga udang windu akan meningkat dan akhirnya akan meningkatkan keuntungan petambak udang windu yang terlibat.

Beberapa hasil penelitian yang menghitung strategi distribusi pemasaran udang windu seperti yang dilakukan oleh Guslan (2015), dengan lokasi penelitian di Desa Pegat Batumbuk Kecamatan Pulau Derawan Kabupaten Berau, dimana hasil penelitian menunjukkan strategi baru yang dapat diterapkan dalam melakukan proses pemasaran yang mana dapat memberikan manfaat kepada pelaku usaha penampung udang windu dalam meningkatkan nilai tambah dari hasil produk udang windu yang dipasarkan. Adapun penerapan analisis SWOT pada penampung udang windu di desa Pegat Batumbuk menghasilkan strategi WO yaitu, menjaga potensi sumberdaya alam dari pencemaran agar dapat meningkatkan pasokan udang windu yang diperoleh. Dukungan dan campur tangan Pemerintah dalam hal ini Dinas Perikanan sangat diperlukan dalam menjalankan sebuah usaha perikanan (penampung).

Penelitian ini bertujuan mengetahui: (i) jumlah lembaga pemasaran pada distribusi pemasaran udang windu, (ii) jalur pemasaran yang ada pada pemasaran udang windu oleh petani kolam di Kelurahan Margomulyo Kecamatan Balikpapan Barat Kota Balikpapan, (iii) marjin pemasaran pada distribusi pemasaran udang windu.

\section{METODE PENELITIAN}

\section{Lokasi dan Rancangan Penelitian}

Lokasi penelitian ini dilakukan pada Kawasan Margomulyo, Kecamatan Balikpapan Barat Kota Balikpapan yang dilaksanakan pada bulan September hingga Desember 2016. Jangka waktu tersebut meliputi tahap persiapan (pengumpulan literature), pengambian data, analisis data hingga penyusunan laporan.

\section{Populasi dan Sampel}

Populasi dalam penelitian ini adalah masyarakat, peneliti dan atau lembaga yang terkait langsung maupun tidak langsung dengan pemanfaatan udang bintik di Kawasan Konservasi Margomulyo, Kota Balikpapan. Responden ditetapkan dengan teknik purposive sampling. Dalam teknik ini, pengambilan sampel dilakukan secara acak yaitu sejumlah 90 responden. dalam penarikan sampel jika populasinya lebih dari 
100 maka dapat diambil 10-15\% atau lebih, sehingga jumlah sampel yang diambil dalam penelitian ini adalah10\% dari jumlah populasi (Arikunto, 2000).

\section{Pengumpulan Data}

Jenis data yang digunakan adalah data primer dan sekunder.Data primer yang dikumpulkan melalui kuisioner dan wawancara langsung adalah data masyarakat nelayan disekitar kawasan, jumlah hasil tangkapan, harga hasil tangkapan, serta distribusi pemasaran. Sementara data sekunder mencakup keadaan wilayah (geografis dan administrasi), kondisi lingkungan dan kondisi ekologis kawasan, kondisi sosial ekonomi masyarakat yang diperoleh dari instansi terkait (BPS \& BAPPEDA Kota Balikpapan , 2012).

\section{Analisa Data}

Model analisis yang digunakan adalah sebagai berikut:

\section{Analisis Margin Pemasaran}

Nilai margin pemasaran (value of marketing margin) merupakan perkalian antara jumlah produk yang dipasarkan. Besar nilai margin pemasaran ini dapat diklasifikasikan kedalam dua bagian, yaitu:

a. Biaya-biaya pemasaran (marketing cost) adalah besarnya biaya-biaya yang dikeluarkan untuk faktor-faktor produksi yang digunakan di dalam pengolahan produk hingga pemasarannya mulai dari petani sampai ke konsumen akhir. Biayabiaya pemasaran ini disebut juga pendapatan atas faktor produksi (return to factors). Termasuk kedalamnya komponen-komponen upah, bunga, sewa dan keuntungan.

b. Pungutan-pungutan

pemasaran (marketing charges) adalah pungutan atau biaya jasa yang diambil oleh berbagai lembaga pemasaran yang terlibat dalam pemasaran produk, seperti pengecer, grosir, pengolah dan pengumpul.

Besarnya margin pemasaran secara matematis dapat dirumuskan sebagai berikut

$$
\mathbf{M}=\mathbf{P r} \boldsymbol{-} \mathbf{P f}
$$

Keterangan :

$\mathrm{M}=$ margin pemasaran
$\operatorname{Pr}=$ harga tingkat konsumen

$\mathrm{Pf}=$ harga ditingkat produsen

\section{Distribusi Margin}

Keterangan :

$$
D M=\frac{P}{M} x 100 \%
$$

$\mathrm{DM}=$ Distribusi marjin

$\mathrm{P}=$ Biaya

$\mathrm{Mi}=$ Marjin

\section{Analisis Share}

Analisis share untuk mengetahui bagian harga yang diterima oleh petani kolam dari harga ditingkat konsumen dan dinyatakan presentase.Farmer's Share mempunyai hubungan negatif dengan marjin pemasara sehingga semakin tinggi marjin pemasaran maka bagian yang diperoleh petani Kolam semakin rendah. Secara sistematis Farmer's Share dapat dirumuskan sebagai berikut :

Keterangan :

$$
F s i=\frac{P f}{P r} \times 100 \%
$$

Fsi $=$ Persentase yang diterima petani $(\%)$

Pf $=$ Harga di tingkat atau yang diterima petani

$\operatorname{Pr}=$ Harga yang dibayarkan oleh konsumen akhir.

\section{HASIL DAN PEMBAHASAN}

Hasil penelitian menunjukan bahwa ada empat pola saluran distribusi udang windu di Kawasan Margomulyo Kota Balikpapan yaitu : Pola saluran distribusi pemasaran I (produsen-konsumen) adalah bentuk saluran distribusi pemasaran paling pendek dan paling sederhana. Saluran distribusi pemasaran dari produsen ke konsumen ini dapat juga disebut sebagai saluran distribusi langsung, disini konsumen akhir langsung melakukan pembelian pada produsen (petani tambak). Pola saluran distribusi pemasaran II( produsen-pengecerkonsumen) adalah bentuk saluran distribusi pemasaran ikan nila dari produsenke pengecer lalu konsumen, ini dapat juga disebut sebagai saluran distribusi tidak langsung, disini pedagang pengecer langsung melakukan pembelian pada petani kolom (produsen), kemudian pedagang pengecer ini mengecerkan/menjualnya kembali melalui 
tempat penjulan yang mereka miliki ke konsumen akhir.Pola saluran distribusi pemasaran III (produsen-pengumpulpengecer-konsumen) pada pola saluran ini pengumpul membeli langsung ke produsen dengan mendatangi rumah produsen atau kolam budidaya usahanya. Kemudian pedagang pengumpul ini menjual kembali ikan nila ke pedagang pengecer yang lalu disalurkan kepada konsumen melalui tempattempat penjualan mereka sendiri. Pola saluran distribusi pemasaran IV (produsenpengumpul-pengecer-pedagang kelilingkonsumen) pola saluran distribusi ini hampir sama dengan saluran distribusi diatas, saluran ini dilakukan oleh pengumpul yang membeli udang windu dari petani tambak lalu menjualnya kembali kepada pengecer setelah itu pedagang keliling membeli dari para pengecer untuk mereka jual kepada konsumen akhir.

\section{PEMBAHASAN}

Dalam pendistribusian udang bintik di Kelurahan Margomulyo Kecamatan Balikpapan Barat Kota Balikpapan Provinsi Kalimantan Timur pada saluran ini bagian yang diterima oleh petani tambak udang Windu Atau bintik sebesar Rp. 25.000,- / Genggam Ukuran Tangan Dewasa demikian juga harga yang dibeli langsung ditingkat konsumen akhir adalah sebesar Rp. 35.000,/ Genggam.

Selisih harga jual dari petani tambak ke pedagang keliling yaitu sebesar Rp. 1.433,- / genggam dan harga jual dari pedagang keliling ke konsumen akhir adalah sebesar Rp. 37.000,- / genggam. Artinya selisih ratarata harga jual dengan harga akhir ke konsumen sebesar 7.800. Dimana selisih marjin adalah sebesar Rp. 9.233,- dan share pedagang keliling sebesar 75,05\%. Dari selisih harga tersebut pedagang keliling masih mengeluarkan biaya-biaya seperti : Biaya Transportasi sebesar Rp. 1.700,-, dengan distribusi marjin sebesar 18,42\% dan sharenya sebesar 4,60 \%, biaya konsumsi sebesar Rp. 810 ,- / genggam adapun distribusi marjinnya sebesar 8,77 \% dan sharenya sebesar 2,19\%, biaya pengepakan / es sebesar Rp 170,- / genggam dan distribusi marjinnya sebesar $1,84 \%$, sharenya sebesar $0,45 \%$ sehingga dapat dilihat keuntungan yang diperolah pedagang keliling adalah sebesar Rp. 6.553,- / genggam. Keuntungan diperoleh dari harga jual ditingkat pedagang keliling distribusi marjinnya adalah sebesar $70,97 \%$.Udang bintik dari distribusi marjin yang diperoleh dari biaya yang dikalikan 100 $\%$ dibagi dengan marjin. Sedangkan nilai konsumen Akhir dari harga pembelian sebesar Rp. 37.000,- maka diperoleh nilai marjin adalah sebesar Rp. 9.233,-

Dalam pendistribusian udang bintik oleh pedagang keliling di Kelurahan Margomulyo Kecamatan Balikpapan Barat Kota Balikpapan Provinsi Kalimantan Timur pada saluran ini pedagang keliling lebih dekat dengan konsumen akhir dengan harga penjulan pedagang keliling ditingkat konsumen lebih tinggi, dengan konsekwensi pedagang keliling memiliki daya jangkauan penjualan yang lebih luas sehingga harga yang ditawarkan lebih tinggi dari harga jual di pasaran dikarenakan pedagang keliling memiliki nilai marjin tranasport lebih besar.

\section{KESIMPULAN}

Tingkat distribusi pemasaran udang windu saluran pola II (Prosusen-PengecerKonsumen) dominan digunakan karena alur distribusi pemasaran tersebut relatif lebih pendek sehingga memotong alur distribusi pemasaran hingga sampai pada tingkat konsumen akhir, sehingga dapat menekan biaya tambahan laianya. Hal dapat dilihat berdasarkan nila share yang diperoleh sebesar $75,05 \%$ dimana nilai tersebut menunjukkan keuntungan bagi petani tambak udang windu (Produsen) yang menjanjikan sebagai pelaku usaha budidaya udang windu. Tingkat distribusi pemasaran udang windu saluran pola I ( Produsen - Konsumen Akhir ) lebih baik karena pada pola ini tidak tergantung pada lembaga distrubusi pemasaran, sehingga tidak memerlukan biaya tambahan lainya, dilain sisi lebih menguntungkan konsumen akhir dengan mendapatkan harga udang windu yang lebih murah.

\section{DAFTAR PUSTAKA}


Arikunto, S. 2000. Prosedur Penelitian Suatu Pendekatan Praktek. Penerbit Rineka Cipta. Yogyakarta.

BLH Kota Balikpapan. 2012. Balikpapan Kota Pantai Menatap ke Depan. Penerbit Pusat Pembelajaran dan Pengembangan Pesisir dan Laut. Balikpapan.

BPS RI. 2016. Data Ekspor Udang. http://bps.go.id/. Diakses pada 10 April 2016.

BPS dan BAPPEDA Kota Balikpapan. (2012). Indeks Pembangunan Manusia Kota Balikpapan Tahun 2012. NP. 64.715.2012.4.
Fauzi, Ahmad. 2006. Ekonomi Sumberdaya Alam dan Lingkungan, Teori dan Aplikasi. Penerbit Gramedia Pustaka Utama. Jakarta.

Guslan, A. 2016. Analisis strategi saluran pemasaran usaha budidaya udang windu di Desa Pegat Batumbuk Kecamatan Pulau Derawan Kabupaten Berau. eJournal Administrasi Bisnis, Vol. 4 No. 4.

Widya, M. Sistem Agribisnis. Https://blog.ub.ac.id/mayaikawid ya/2014/02/24/sistem-agribisnis/. Diakses pada 10 April 2016.

\section{LAMPIRAN}

Tabel 1. Distribusi pola saluran pemasaran.

\begin{tabular}{ccccc}
\hline No. & $\begin{array}{c}\text { Jenis Saluran } \\
\text { Pemasaran }\end{array}$ & $\begin{array}{c}\text { Jumlah } \\
\text { Petani }\end{array}$ & $\begin{array}{c}\text { Persentase } \\
(\%)\end{array}$ & $\begin{array}{c}\text { Nilai Jual } \\
\text { Rata-Rata ( Per-Genggam) }\end{array}$ \\
\hline & & & & \\
1. & POLA I & 28 & 31,11 & $29.500,-$ \\
2. & POLA II & 42 & 46,67 & $30.857,-$ \\
3. & POLA III & 15 & 16,66 & $21.800,-$ \\
4. & POLA IV & 5 & 5,56 & $19.900,-$ \\
\hline & Jumlah & 90 & 100 & - \\
\hline
\end{tabular}

Sumber : Analisis Data Primer (2016).

Tabel 2. Distribusi harga pemasaran pola I.

\begin{tabular}{c|c|ccc}
\hline No. & Lembaga Pemasaran & Rp/Ggm & Distribusi Marjin (\%) & Share (\%) \\
\hline 1. & $\begin{array}{c}\text { Petani tambak udang bintik } \\
-\quad \text { Harga Jual }\end{array}$ & $25.000,-$ & & \\
2. & $\begin{array}{c}\text { Konsumen Akhir } \\
-\quad \text { Harga Beli }\end{array}$ & $35.000,-$ & & \\
& & & & \\
\hline
\end{tabular}

Sumber : Analisis Data Primer (2016)

Tabel 3. Marjin Pemasaran, Distribusi Marjin dan Share udang bintik Di Kelurahan Margomulyo Kecamatan Balikpapan Barat Kota Balikpapan Pada Pola Saluran II ( Produsen Pengecer - Konsumen ). 


\begin{tabular}{|c|c|c|c|c|}
\hline No. & Lembaga Pemasaran & ( Rp/Gm) & Distribusi Marjin (\%) & Share $(\%)$ \\
\hline 1. & Petani udang bintik & & & \\
\hline \multirow{9}{*}{2.} & - Rata-Rata Harga Jual & $27.767,-$ & & 75,05 \\
\hline & Pedagang Eceran & & & \\
\hline & - Harga Beli & $27.767,-$ & & \\
\hline & - Biaya Transportasi & $1.666,-$ & 18,04 & 4,50 \\
\hline & - Biaya Konsumsi & 633,- & 6,86 & 1,71 \\
\hline & $\begin{array}{l}\text { - } \quad \text { Biaya Pengepakan / } \\
\text { Es }\end{array}$ & $233,-$ & 2,52 & 0,63 \\
\hline & - Biaya Retribusi & $220,-$ & 2,38 & 0,60 \\
\hline & - Biaya Sewa Tempat & 600,- & 6,50 & 1,61 \\
\hline & - Keuntungan & $5.881,-$ & 63,70 & 15,90 \\
\hline \multirow[t]{3}{*}{3.} & Konsumen Akhir & & & \\
\hline & - Beli & $37.000,-$ & & \\
\hline & Marjin Pemasaran & 9.233 & 100 & 100 \\
\hline
\end{tabular}

Sumber : Analisis Data Primer (2016).

Tabel 4. Marjin Pemasaran, Distribusi Marjin dan Share Ikan Nila Di Kelurahan Margomulyo Kecamatan Balikpapan Barat Kota Balikpapan Pada Pola Saluran III (ProdusenPengumpul-Pengecer-Konsumen).

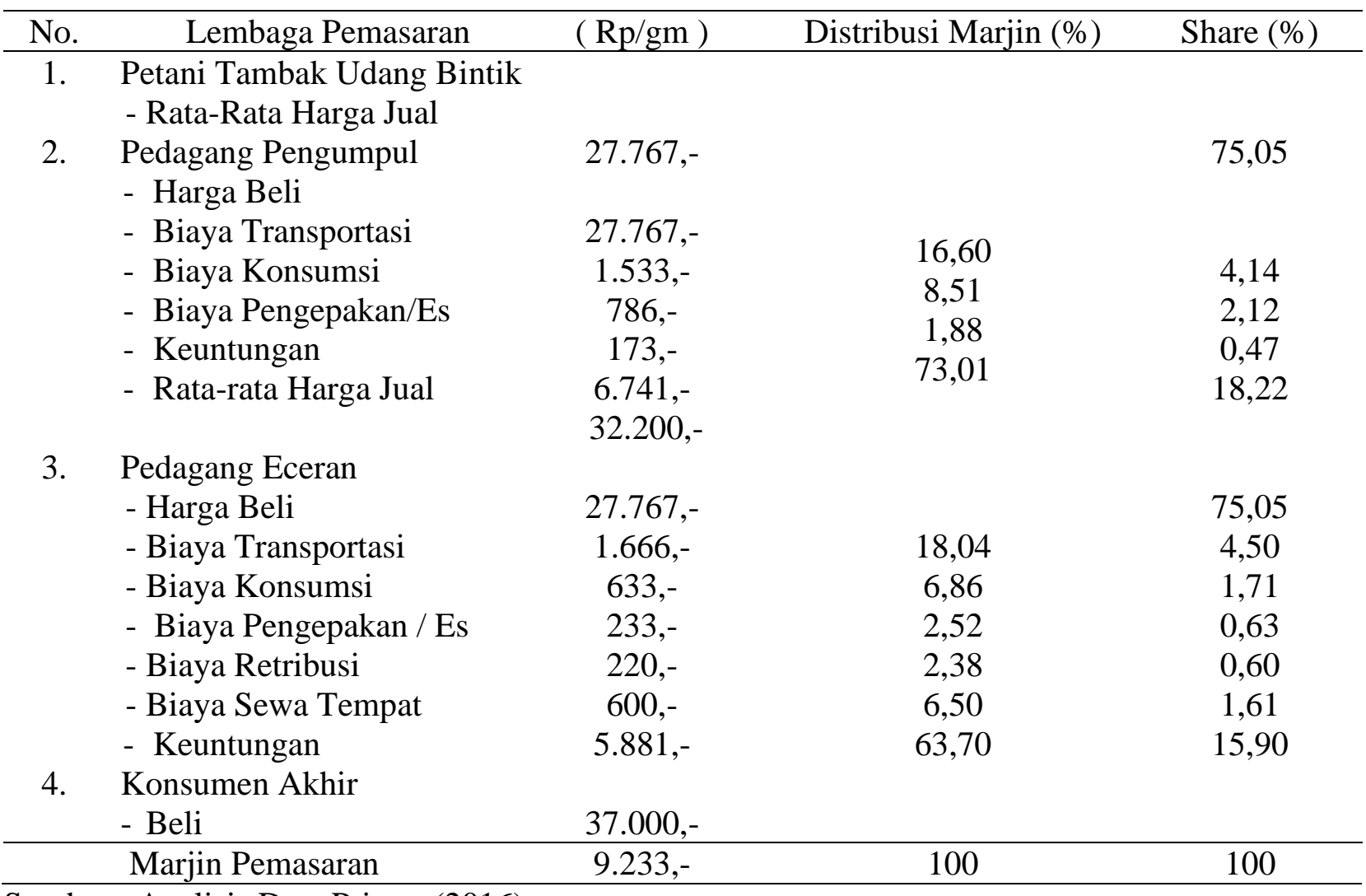

Sumber : Analisis Data Primer (2016).

Tabel 5. Marjin pemasaran, distribusi marjin dan share udang bintik Di Kelurahan Margomulyo Kecamatan Balikpapan Barat Kota Balikpapan Pada Pola Saluran IV (PengumpulPengecer-Pedagang Keliling-Konsumen).

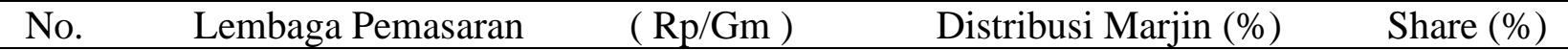




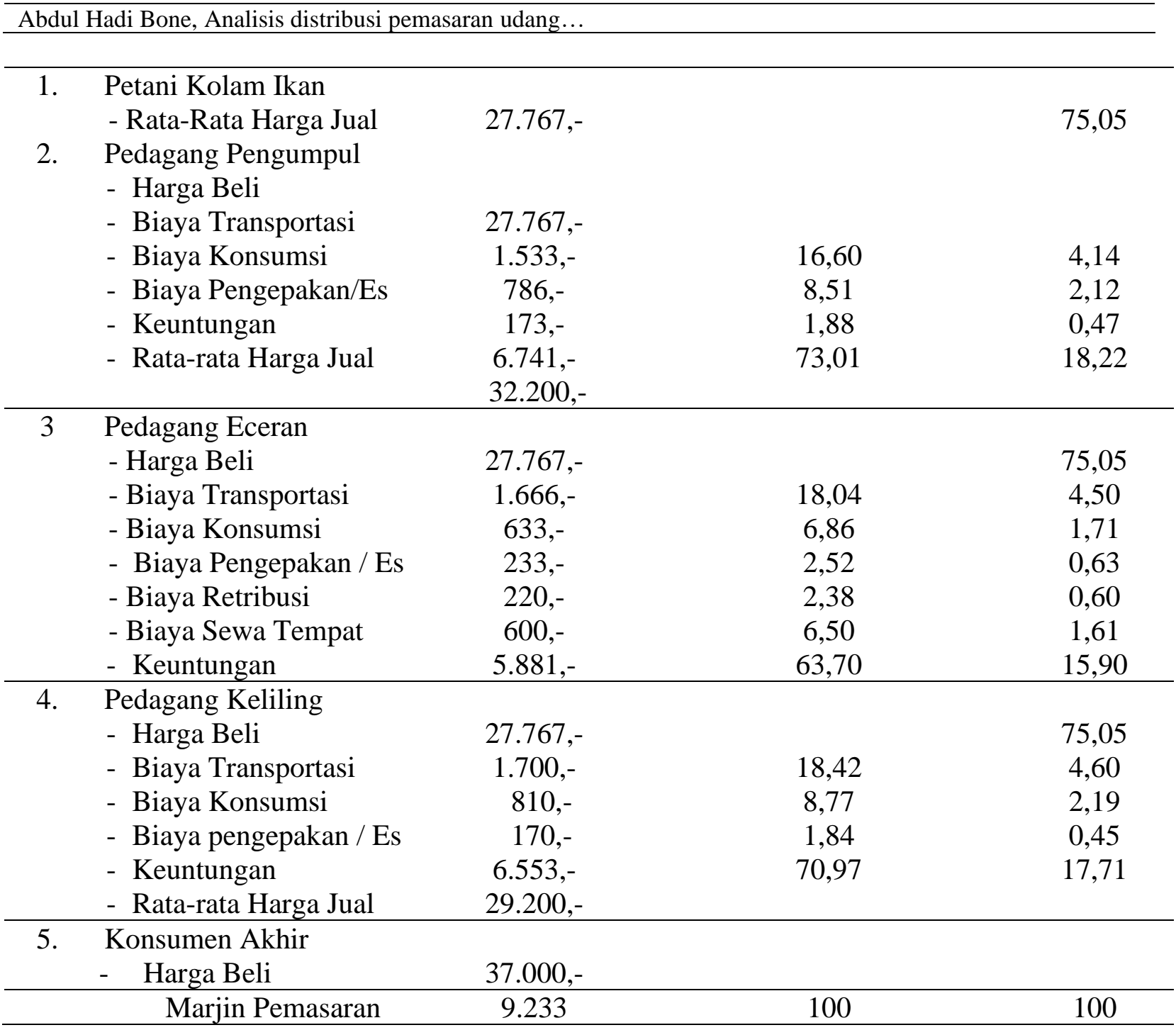

Sumber : Analisis Data Primer (2016). 